\title{
Nurse-perceived Patient Adverse Events and Nursing Practice Environment
}

\author{
Jeong-Hee Kang ${ }^{1 *}$, Chul-Woung Kim ${ }^{2,3}$, Sang-Yi Lee ${ }^{4}$ \\ ${ }^{1}$ Department of Nursing Science, Gyeongju University, Gyeongju; '2Department of Preventive Medicine, Chungnam National University School of \\ Medicine, Daejeon; ${ }^{3}$ Research Institute for Medical Sciences, Chungnam National University School of Medicine, Daejeon; ${ }^{4}$ Department of Health \\ Policy and Management, Jeju National University School of Medicine, Jeju, Korea
}

Objectives: To evaluate the occurrence of patient adverse events in Korean hospitals as perceived by nurses and examine the correlation between patient adverse events with the nurse practice environment at nurse and hospital level.

Methods: In total, 3096 nurses working in 60 general inpatient hospital units were included. A two-level logistic regression analysis was performed.

Results: At the hospital level, patient adverse events included patient falls (60.5\%), nosocomial infections (51.7\%), pressure sores (42.6\%) and medication errors (33.3\%). Among the hospital-level explanatory variables associated with the nursing practice environment, 'physician-nurse relationship' correlated with medication errors while 'education for improving quality of care' affected patient falls.

Conclusions: The doctor-nurse relationship and access to education that can improve the quality of care at the hospital level may help decrease the occurrence of patient adverse events.

Key words: Nursing practice environment, Medication error, Patient fall, Nosocomial infection, Pressure sore

\section{INTRODUCTION}

Patient adverse events are important indicators predictive of the quality of care [1]. Patient adverse events are unintended injuries or complications resulting in death, disability, or prolonged hospital stays that arise from health care management. The rate of adverse events among hospital patients is an important indicator of patient safety [2]. Patient adverse events

Received: May 8, 2014 Accepted: August 12, 2014

Corresponding author: Chul-Woung Kim, MD, PhD

266 Munhwa-ro, Jung-gu, Daejeon 301-747, Korea

Tel: +82-42-580-8268, Fax: +82-42-583-7561

E-mail: woung@cnu.ac.kr

*Current affiliation: Department of Nursing Science, Youngdong University, Yeongdong, Korea

This is an Open Access article distributed under the terms of the Creative Commons Attribution Non-Commercial License (http://creativecommons.org/licenses/by$\mathrm{nc} / 3.0 /$ ) which permits unrestricted non-commercial use, distribution, and reproduction in any medium, provided the original work is properly cited. not only are directly disadvantage patients but also financially burden the health care system [3].

Patient adverse events emerged as an important issue when a report entitled, "To Err is Human" was published by the US Institute of Medicine in 1999 on the status of patient safety and the potential for improvement measures. According to the report, 44000 to 98000 people had died annually due to medical malpractice and approximately 7000 had died due to medication errors annually. The report also revealed that treatment costs caused by preventable patient adverse events were estimated as much as 18.7 to 31.9 billion dollars annually [4].

There are two ways to measure patient adverse events. One is to calculate an objective incidence using the medical records of discharged patients. In doing so, three steps are used to measure an objective incidence of patient adverse events. First, investigators interview the head nurse and consult medical records to detect adverse events. For patients who were screened as positive, investigators interview the doctor who managed 
the patient to confirm of the adverse event. Second, detection investigators visit the ward on day 1 of the survey, twice in the first week, and then weekly for up to 4 weeks. Third, a review of the medical records begins on day 30 of the study using detection and confirmation questionnaires [2]. Major studies that have used this method include the Harvard Medical Practice Study [5] and the Study on Adverse Events and Negligent Care in Utah and Colorado [6]. According to the findings of these studies, the incidence of patient adverse events occurring in acute care hospitals in Utah and Colorado were 2.9\% and 3.7\% in New York [5,6]. Moreover, $6.6 \%$ of the events in Utah and Colorado and $13.6 \%$ of the events in New York led to patient mortality; thus, more than half of these patient adverse events were preventable $[5,6]$.

The second way of measuring patient adverse events is to survey hospital nurses about their perception of the incidence of hospital accidents and patient side effects. For example, the International Hospital Outcome Study, on 711 hospitals from five different countries, found that medication errors perceived by nurses over the previous year were $15.7 \%, 19.3 \%$, and $5.1 \%$ and nosocomial infections were $34.7 \%, 33.0 \%$, and $27.9 \%$ in the US, Canada, and Germany, respectively. In addition, patient falls occurred $20.4 \%$ in the US, 27.9\% in Canada, and $15.0 \%$ in Germany [7].

The nursing work environment is one factor associated with patient adverse events in hospitals. Hospitals that provide a favorable nursing practice environment had a $5 \%$ lower occurrence of patient falls than those that did not [8]. A favorable nursing practice environment not only decreases patient adverse events such as nosocomial infections and medication errors [9] but also enhances the overall quality of care [10].

With the adoption of the healthcare accreditation system in 2004, South Korea (hereafter Korea) began considering patient adverse events an item subject to evaluation. Nevertheless, no official statistics on the scale and magnitude of patient adverse events in Korea are available [11]. Several studies investigated patient adverse events related to medication errors, falls, nosocomial infections, and pressure sores $[2,12,13]$; however, no study has investigated variables associated with the nursing practice environment that affect patient adverse events.

Thus, this study aimed to measure patient adverse events such as medication errors, nosocomial infections, patient falls, and pressure sores in Korean hospitals using self-reported data from nurses as well as analyze the correlation between the nursing practice environment and patient adverse events.

\section{METHODS}

\section{Study Participants and Data Collection}

Among the 22520 nurses who were registered in the Korea Health and Medical Workers Union as of 2010, 11731 nurses who participated in the unions educational program were surveyed, and 5654 of them responded ( $48.2 \%$ response rate). The data used for this study was collected through a survey of the union nurses who participated in the unions educational program. The surveyed nurses were explained the study purpose, and the survey was completed with their prior informed consent. The self-administered questionnaire consisting of multiple sections was approved by the Chungnam National University Institutional review board (no. 13-03).

In total, 3096 nurses from 60 hospitals in Korea were analyzed. Participants included nurses working in internal medicine, surgery, pediatrics, and obstetrics/gynecology; those working in special wards $(n=1666)$ and outpatient departments $(n=584)$ were excluded from the analysis. In addition, supervising nurses $(n=55)$ and staff nurses $(n=253)$ along with any the nurses working at a hospital with fewer than 10 survey respondents per hospital were further excluded from the analysis because the nursing environment tend to significantly vary depending on the department and status of the nurses (supervising nurses vs. staff nurses).

\section{Study Variables}

Patient adverse events perceived by these nurses included medication errors, patient falls, nosocomial infections, and pressure sores. In the self-reported questionnaire, nurses were asked "How often did you perceive hospital accidents and patient side effects over the past one year?", and answers were collected as either none/never (1), very rarely (2), occasionally (3), or frequently (4). These answers were further stratified as a binary variable; none/never and very rarely as well as occasionally and frequently were merged into one variable, respectively.

Medication errors were defined as an error in the dosage or time of administration or if a drug was administered to the wrong patient, regardless of resulting side effects. Patient falls were defined as any patient fall, regardless of resulting injury. Nosocomial infections were defined as an infection originating in the hospital, such as a urinary tract infection, respiratory infection, or wound infection. Last, pressure sores were defined as the development of a stage 2 to stage 4 pressure sore. 


\section{Explanatory variables at the nurse level}

The general characteristics of the nurses included gender, age, and education. In addition, the nurses' position, clinical experience, work department, nurse-perceived nursing practice environment, and extent of nurses' experience for non-nursing tasks were used to identify job characteristics.

To measure factors related to the nursing practice environment, the Korean General Inpatients Unit Nursing Work Index (KGU-NWI) was used. This index is composed of 26 items that measures six subfactors: participation in the decision-making process, nursing process, education to improve the quality of care, nursing-staffing adequacy, organizational support and management of the hospital, and the doctor-nurse relationship [14]. The arithmetic mean of each factor was calculated at the nurse and hospital levels.

Concerning the measurement of extent of nurses' experience for non-nursing tasks, the International Hospital Outcomes Study conducted on nurses in the US, Canada, and Germany between 1998 and 1999 was used [7]. The non-nursing tasks included delivering and retrieving food trays, housekeeping duties, transporting patients, and coordinating or performing other ancillary services. Nurses were asked how often they had performed any of these non-nursing tasks over the previous 12 months. Their answers were collected as never (1), very rarely (2), occasionally (3), or frequently (4). The arithmetic mean for each item was also calculated for all non-nursing tasks at both at the nurse and hospital levels.

\section{Explanatory variables at the hospital level}

The general characteristics of the hospitals were identified by the bed-to-nurse ratio (general ward), hospital type, and ownership. These variables were provided by the Health Insurance Review and Assessment Service in Korea [15]. The bed-tonurse ratio was collected as per one nurse, and a high nursegrade indicates that the bed-to-nurse ratio is low. The bed-tonurse ratio is one of the general indicators of hospital quality. For the purposes of our analysis, it was categorized into four levels as $<3.0,3.0$ to $3.4,3.5$ to 3.9 , and $\geq 4.0$. Hospital ownership was divided as either a public or private hospital, and the type of hospital was either a tertiary general hospital or nontertiary general hospital.

\section{Statistical Analysis}

Nurse-perceived patient adverse events were organized through frequency analyses. The correlation between patient adverse events and the nursing practice environment was also examined using two-level logistic regression analysis with the hierarchical linear model.

With medication errors as the binary dependent variable, a multilevel model used to analyze nurse-perceived medication errors as follows.

\section{Nurse level}

Logit (medication error) $=\beta_{0 j}+\beta_{1 j}$ (gender $\left.r_{i j}\right)+\beta_{2 j}$ (education $\left._{i j}\right)+\beta_{3 j}\left(\right.$ position $\left._{i j}\right)+\beta_{4 j}\left(\right.$ clinical experience $\left._{i j}\right)+\beta_{5 j}($ nonnursing task-nurse $\mathrm{ij})+\beta_{6 \mathrm{j}}\left(\right.$ pediatrics $\left._{\mathrm{ij}}\right)+\beta_{7 \mathrm{j}}\left(\right.$ surgery $\left._{\mathrm{ij}}\right)+\beta_{8 \mathrm{j}}(\mathrm{ob}-$ stetrics and gynecology $\left.y_{i j}\right)+\beta_{9 j}\left(\right.$ NWPDM-nurse $\left.e_{i j}\right)+\beta 0_{10 j}(N W N P-$ nurse $\left._{i j}\right)+\beta 0_{11 j}\left(\right.$ NWSTF-nurse $\left.{ }_{i j}\right)+\beta 0_{12 j}\left(\right.$ NWEDU-nurse $\left.{ }_{i j}\right)+\beta 0_{13 j}$ $\left(\right.$ NWOSM-nurse $\left._{i j}\right)+\beta 0_{14 j}\left(\right.$ NWDNR-nurse $\left.e_{i j}\right)$

\section{Hosptial level}

$\beta_{0 j}=\gamma_{00}+\gamma_{01}$ (ownership $\left.p_{j}\right)+\gamma_{02}$ (bed-to-nurse ratio $\left.{ }_{j}\right)+\gamma_{03}$ $\left(\right.$ type $\left._{\mathrm{j}}\right)+\gamma_{04}$ (non-nursing task-hospitalj) $+\gamma_{05}$ (NWPDM-hospitalj $)+\gamma_{06}\left(\right.$ NWNP-hospitalj) $+\gamma_{07}\left(\right.$ NWSTF-hospitalj) $+\gamma_{08}($ NWEDU-hospitalj) $+\gamma_{09}\left(\right.$ NWOSM-hospitalj) $+\gamma_{010}($ NWDNR-hospitalj $)$ $+\mathrm{u}_{0 \mathrm{j}}$

Variables related to the nursing practice environment were participation in the decision-making processes (NWPDM), nursing process (NWNP), nurse-staffing adequacy (NWSTF), education to improve the quality of care (NWEDU), organizational support and management of the hospital (NWOSM), and the doctor-nurse relationship (NWDNR). When analyzed at the nurse or hospital level, each variable was indicated with nurse or hospital at the end, respectively.

The adequacy of the multilevel analysis model was assessed by rejecting the null hypothesis at the hospital level $\left(\mathrm{H}_{0}: \mathrm{T}_{00}=0\right)$ that random variance of dependent variables at the hospital level is zero. If rejected, it can be concluded that there is significant difference in dependent variables by hospital and that the multilevel analysis is adequate.

\section{RESULTS}

\section{General Characteristics}

Among the surveyed hospitals, $61.7 \%$ and $38.3 \%$ were nontertiary general hospitals and tertiary general hospitals, respectively. In addition, $56.7 \%$ were private and $43.3 \%$ were public. For the bed-to-nurse ratio, $33.3 \%$ had a $\geq 4$ or 3.0 to 3.4 ratio, and $16.7 \%$ had a 3.5 to 3.9 or $<3.0$ ratio. 
At the hospital level, the frequency of patient adverse events perceived by nurses was comprised of patient falls $(60.5 \%)$, nosocomial infections $(51.7 \%)$, pressure sores $(42.6 \%)$, and medication errors (33.3\%).

The average scores of the six factors measured in the KGUNWI at the hospital level were 2.60, 2.55, 2.55, 2.13, 1.93, and 1.64 for the nursing process, doctor-nurse relationship, organizational support and management of the hospital, education to improve the quality of care, participation in the decision-making process, and nursing-staff adequacy, respectively. Thus, nursingstaff adequacy and participation in the decision-making process were most lacking in the nursing environment (Table 1).

In the univariate analysis, the type of hospital $(p<0.01)$, ownership of the hospital $(p<0.001)$, and bed-to-nurse ratio $(p<0.001)$ were associated with medication errors. Gender $(p<0.05)$, age $(p<0.001)$, position $(p<0.001)$, clinical experience $(p<0.001)$, work department $(p<0.001)$, ownership of the hospital $(p<0.001)$, and bed-to-nurse ratio $(p<0.001)$ were associated with patient falls. Age $(p<0.001)$, position $(p<0.05)$, clinical experience $(p<0.001)$, work department $(p<0.001)$, and the bed-to-nurse ratio $(p<0.05)$ were associated with nosocomial infections. The clinical experience $(p<0.05)$, work department $(p<0.001)$, type of hospital $(p<0.054)$, and ownership of the hospital $(p<0.01)$ were associated with pressure sores (Table 2).

\section{Relationship Between Nurse-perceived Patient} Adverse Events and Nurse Practice Environment

Hospital-level variables affecting nurse-perceived medication errors were the doctor-nurse relationship and ownership of the hospital. The odds ratio (OR) of the doctor-nurse relationship, one of the variables associated with nursing practice environment, was $0.33(p<0.05)$. There were fewer nurse-perceived medication errors in public hospitals than there were in private hospitals $(\mathrm{OR}, 0.60 ; p<0.01)$. Among the nursing work environment variables at the nurse level, the nursing process $(\mathrm{OR}, 0.79$; $p<0.05)$, organizational support and management of the hospital (OR, 0.76; $p<0.05$ ), and doctor-nurse relationship (OR, 0.72; $p<0.05$ ) were found to affect nurse-perceived medication errors. Moreover, nurse-staffing adequacy was correlated with medication errors (OR, 1.30; $p<0.05)$.

Hospital-level variables affecting nurse-perceived patient falls were education to improve the quality of care and the hospital type. The OR for education to improve the quality of care was $0.31(p<0.05)$. Nurse-perceived patient falls in non-tertiary general hospitals were greater than that in tertiary general hospitals were $(\mathrm{OR}, 1.50 ; p<0.05)$.

No hospital-level nurse practice environment variable affected the rate of nurse-perceived nosocomial infections. However, at the nurse level, the doctor-nurse relationship was found to affect nurse-perceived nosocomial infections (OR, 0.78; $p<0.05$ ).

No hospital-level variable was found to affect pressure sores. However, at the nurse level, the nursing process $(\mathrm{OR}, 0.81 ; p<0.05)$

Table 1. General characteristics of the 60 hospitals

\begin{tabular}{|c|c|c|c|c|}
\hline Characteristics & & & n $(\%)$ & \\
\hline Type & $\begin{array}{l}\text { Tertiary general hospital } \\
\text { Non-tertiary general hospital }\end{array}$ & & $\begin{array}{l}23(38.3) \\
37(61.7)\end{array}$ & \\
\hline Ownership & $\begin{array}{l}\text { Private } \\
\text { Public }\end{array}$ & & $\begin{array}{l}34(56.7) \\
26(43.3)\end{array}$ & \\
\hline Bed-to-nurse ratio & $\begin{array}{l}<3.0 \\
3.0-3.4 \\
3.5-3.9 \\
\geq 4.0\end{array}$ & & $\begin{array}{l}10(16.7) \\
20(33.3) \\
10(16.7) \\
20(33.3)\end{array}$ & \\
\hline & & Mean \pm SD & Percentile 25 & Percentile 75 \\
\hline Nurse-perceived patient adverse events $(\%)^{1}$ & $\begin{array}{l}\text { Medication errors } \\
\text { Patients falls } \\
\text { Nosocomial infections } \\
\text { Pressure sores }\end{array}$ & $\begin{array}{l}33.3 \pm 13.6 \\
60.5 \pm 15.2 \\
51.7 \pm 13.5 \\
42.6 \pm 16.8\end{array}$ & $\begin{array}{l}23.3 \\
50.4 \\
43.9 \\
30.8\end{array}$ & $\begin{array}{l}44.9 \\
73.6 \\
62.1 \\
53.3\end{array}$ \\
\hline Korean general unit-nursing work index & $\begin{array}{l}\text { Participation in the decision-making process } \\
\text { Nursing process } \\
\text { Nurse-staffing adequacy } \\
\text { Education to improve the quality of care } \\
\text { Organizational support and management of the hospital } \\
\text { Doctor-nurse relationship }\end{array}$ & $\begin{array}{l}1.93 \pm 0.18 \\
2.60 \pm 0.22 \\
1.64 \pm 0.20 \\
2.13 \pm 0.24 \\
2.25 \pm 0.26 \\
2.25 \pm 0.16\end{array}$ & $\begin{array}{l}1.78 \\
2.45 \\
1.51 \\
1.96 \\
2.05 \\
2.15\end{array}$ & $\begin{array}{l}2.03 \\
2.75 \\
1.78 \\
2.30 \\
2.44 \\
2.37\end{array}$ \\
\hline
\end{tabular}

${ }^{1}$ Nurses were asked whether any adverse events involving them or their patients had occurred occasionally or frequently in the past year. 
Table 2. Proportion of nurse-perceived patient adverse events by explanatory variables $(\mathrm{n}=3096)$

\begin{tabular}{|c|c|c|c|c|c|c|c|c|c|c|}
\hline \multirow{2}{*}{ Variables } & & \multirow{2}{*}{$\mathbf{n}$} & \multicolumn{2}{|c|}{ Medication errors ${ }^{1}$} & \multicolumn{2}{|c|}{ Patient falls ${ }^{1}$} & \multicolumn{2}{|c|}{ Nosocomial infections ${ }^{1}$} & \multicolumn{2}{|c|}{ Pressure sores $^{1}$} \\
\hline & & & $\%$ & $p$-value & $\%$ & $p$-value & $\%$ & $p$-value & $\%$ & $p$-value \\
\hline Gender & $\begin{array}{l}\text { Female } \\
\text { Male }\end{array}$ & $\begin{array}{r}3082 \\
14\end{array}$ & $\begin{array}{l}34.9 \\
35.7\end{array}$ & 0.95 & $\begin{array}{l}59.2 \\
28.6\end{array}$ & 0.03 & $\begin{array}{l}53.7 \\
28.6\end{array}$ & 0.10 & $\begin{array}{l}44.6 \\
35.7\end{array}$ & 0.60 \\
\hline Age $(y r)^{2}$ & $\begin{array}{l}<25 \\
25-35 \\
36-45 \\
\geq 45\end{array}$ & $\begin{array}{r}728 \\
1257 \\
914 \\
150\end{array}$ & $\begin{array}{l}35.0 \\
36.2 \\
33.4 \\
31.7\end{array}$ & 0.47 & $\begin{array}{l}51.5 \\
59.2 \\
63.3 \\
69.7\end{array}$ & $<0.001$ & $\begin{array}{l}41.5 \\
52.8 \\
62.7 \\
66.2\end{array}$ & $<0.001$ & $\begin{array}{l}38.8 \\
46.8 \\
46.8 \\
41.5\end{array}$ & 0.002 \\
\hline Position & $\begin{array}{l}\text { Staff nurse } \\
\text { Charge nurse }\end{array}$ & $\begin{array}{r}2873 \\
223\end{array}$ & $\begin{array}{l}34.7 \\
37.3\end{array}$ & 0.44 & $\begin{array}{l}57.9 \\
74.1\end{array}$ & $<0.001$ & $\begin{array}{l}52.9 \\
61.8\end{array}$ & 0.01 & $\begin{array}{l}44.5 \\
44.5\end{array}$ & 0.99 \\
\hline Clinical experience $(y r)^{2}$ & $\begin{array}{l}<3 \\
3-6 \\
7-9 \\
\geq 10\end{array}$ & $\begin{array}{l}702 \\
981 \\
451 \\
650\end{array}$ & $\begin{array}{l}35.6 \\
36.8 \\
32.1 \\
34.1\end{array}$ & 0.33 & $\begin{array}{l}53.1 \\
62.1 \\
63.2 \\
65.7\end{array}$ & $<0.001$ & $\begin{array}{l}43.8 \\
56.2 \\
63.0 \\
63.1\end{array}$ & $<0.001$ & $\begin{array}{l}41.8 \\
48.3 \\
48.1 \\
46.2\end{array}$ & 0.049 \\
\hline Hospital type ${ }^{2}$ & $\begin{array}{l}\text { Tertiary general hospital } \\
\text { Non-tertiary general hospital }\end{array}$ & $\begin{array}{l}1816 \\
1134\end{array}$ & $\begin{array}{l}37.3 \\
32.1\end{array}$ & 0.004 & $\begin{array}{l}57.7 \\
59.6\end{array}$ & 0.13 & $\begin{array}{l}53.0 \\
53.8\end{array}$ & 0.70 & $\begin{array}{l}45.7 \\
41.9\end{array}$ & 0.05 \\
\hline Ownership & $\begin{array}{l}\text { Private } \\
\text { Public }\end{array}$ & $\begin{array}{l}2056 \\
1040\end{array}$ & $\begin{array}{l}39.2 \\
26.1\end{array}$ & $<0.001$ & $\begin{array}{l}61.5 \\
54.2\end{array}$ & $<0.001$ & $\begin{array}{l}52.1 \\
56.5\end{array}$ & 0.23 & $\begin{array}{l}43.5 \\
46.6\end{array}$ & 0.002 \\
\hline Bed-to-nurse & $\begin{array}{l}<3.0 \\
3.0-3.4 \\
3.5-3.9 \\
\geq 4.0\end{array}$ & $\begin{array}{r}826 \\
1363 \\
424 \\
483\end{array}$ & $\begin{array}{l}38.5 \\
38.3 \\
29.9 \\
23.1\end{array}$ & $<0.001$ & $\begin{array}{l}55.7 \\
59.9 \\
61.6 \\
60.5\end{array}$ & $<0.001$ & $\begin{array}{l}51.7 \\
53.6 \\
58.0 \\
53.0\end{array}$ & 0.03 & $\begin{array}{l}40.5 \\
46.3 \\
50.6 \\
41.2\end{array}$ & 0.11 \\
\hline
\end{tabular}

'Nurses were asked whether any adverse events involving them or their patients had occurred occasionally or frequently in the past year.

${ }^{2} \mathrm{Age}$, education, clinical experience, and hospital type had 47, 38, 312, and 146 missing cases, respectively.

and doctor-nurse relationship $(\mathrm{OR}, 0.75 ; p<0.05)$ affected nurseperceived pressure sores.

After evaluating the multilevel analysis model, the model was deemed adequate for analyzing the four nurse-perceived patient adverse events (medication errors, patient falls, nosocomial infections, and pressure sores) because the null hypothesis was rejected $(p<0.05)$. Thus, nurse-perceived medication errors, patient falls, nosocomial infections, and pressure sores were significantly different between hospitals (Table 3 ).

\section{DISCUSSION}

This study examined nurse-perceived patient adverse events. Nurse-perceived patient adverse events in Korean hospitals were high relative to those in foreign hospitals. Among various adverse events, nurse-perceived medication errors in Korea were $34.2 \%$, which is higher than that in Switzerland (30\%), Canada (19.3\%), the US (17.5\%), and Germany (5.1\%). Nurseperceived patient falls were $58.0 \%$ in Korea, which is much higher than that in Switzerland (44\%), Canada (27.9\%), the US (20.4\%), and Germany (15.0\%). Korea had a rate of nurse-perceived nosocomial infections of $52.5 \%$, which is slightly lower than that in Switzerland at 58\%, but still higher than that in the US (34.7\%), Canada (33.0\%), and Germany (27.9\%). Moreover, nurse-perceived pressure sores were $43.7 \%$ in Korea, which is lower than that in Switzerland at 24\% (comparisons from the other countries were not available for pressure sores) $[7,16]$.

Nurse-perceived patient adverse events were higher than the rate measured using medical records. The occurrence of patient adverse events based on medical records was $2.9 \%$ to $16.6 \%[5,6,17-20]$, but the occurrence based on nurses perceptions was $5.1 \%$ to $34.2 \%$ for medication errors, $27.9 \%$ to $58 \%$ for nosocomial infections, and $15.0 \%$ to $58 \%$ for patient falls $[7,16,21,22]$. One reason for this difference might be that all of the nurses in the ward can become aware of one case of an adverse event in a hospital.

Among the four adverse events, patient falls were the most frequently reported by Korean nurses, followed by nosocomial 
Table 3. Relationship between Korean General Inpatients Unit-Nursing Work Index variables and nurse-perceived patient adverse events

\begin{tabular}{|c|c|c|c|c|c|c|c|c|}
\hline \multirow{2}{*}{ Fixed effect } & \multicolumn{2}{|c|}{ Medication errors } & \multicolumn{2}{|c|}{ Patient falls } & \multicolumn{2}{|c|}{ Nosocomial infections } & \multicolumn{2}{|c|}{ Pressure sores } \\
\hline & OR & $95 \% \mathrm{CI}$ & OR & $95 \% \mathrm{CI}$ & OR & $95 \% \mathrm{Cl}$ & OR & $95 \% \mathrm{CI}$ \\
\hline \multicolumn{9}{|l|}{ Hospital-level variables } \\
\hline Ownership (reference = private) & $0.60^{* *}$ & $0.45,0.82$ & 0.73 & $0.52,1.02$ & 1.03 & $0.76,1.39$ & 1.13 & $0.79,1.64$ \\
\hline Type(reference $=$ tertiary general hospitals) & 1.28 & $0.88,1.85$ & $1.50^{*}$ & $1.06,2.12$ & 1.09 & $0.78,1.52$ & 0.89 & $0.63,1.27$ \\
\hline Bed-to-nurse ratio & 0.92 & $0.76,1.11$ & 0.92 & $0.77,1.11$ & 0.90 & $0.80,1.02$ & 0.93 & $0.76,1.15$ \\
\hline NWPDM-hospital & 1.09 & $0.28,4.28$ & 2.58 & $0.60,11.10$ & 1.49 & $0.33,6.78$ & 0.41 & $0.07,2.43$ \\
\hline NWNP-hospital & 2.46 & $0.87,6.96$ & 2.07 & $0.48,8.96$ & 1.23 & $0.35,4.27$ & 2.99 & $0.96,9.32$ \\
\hline NWSTF-hospital & 0.76 & $0.24,2.41$ & 0.60 & $0.21,1.66$ & 1.71 & $0.75,3.89$ & 1.50 & $0.52,4.38$ \\
\hline NWEDU-hospital & 1.06 & $0.44,2.57$ & $0.27^{*}$ & $0.10,0.77$ & 0.57 & $0.23,1.38$ & 0.45 & $0.16,1.27$ \\
\hline NWOSM-hospital & 0.78 & $0.36,1.66$ & 0.73 & $0.37,1.47$ & 0.45 & $0.19,1.08$ & 1.24 & $0.39,3.89$ \\
\hline NWDNR-hospital & $0.33^{*}$ & $0.12,0.93$ & 0.34 & $0.09,1.32$ & 0.79 & $0.25,2.49$ & 0.71 & $0.16,3.10$ \\
\hline \multicolumn{9}{|l|}{ Nurse-level variables } \\
\hline NWPDM-nurse & 0.94 & $0.74,1.19$ & 0.82 & $0.61,1.09$ & 1.04 & $0.79,1.37$ & 1.12 & $0.88,1.43$ \\
\hline NWNP-nurse & $0.79 *$ & $0.66,0.95$ & 0.96 & $0.78,1.17$ & 0.81 & $0.65,1.01$ & $0.81^{*}$ & $0.68,0.97$ \\
\hline NWSTF-nurse & $1.30^{*}$ & $1.06,1.60$ & 1.09 & $0.88,1.34$ & 1.11 & $0.91,1.36$ & 0.97 & $0.82,1.14$ \\
\hline NWEDU-nurse & 0.99 & $0.81,1.22$ & 0.90 & $0.71,1.14$ & 0.82 & $0.62,1.07$ & 0.89 & $0.70,1.14$ \\
\hline NWOSM-nurse & $0.76^{*}$ & $0.60,0.97$ & 1.00 & $0.81,1.23$ & 0.85 & $0.67,1.08$ & 0.86 & $0.69,1.08$ \\
\hline NWDNR-nurse & $0.72^{* *}$ & $0.60,0.86$ & 0.93 & $0.76,1.14$ & $0.79 *$ & $0.65,0.96$ & $0.75^{*}$ & $0.60,0.94$ \\
\hline Random effect $\quad T_{00}=\operatorname{Var}\left(r_{0}\right)$ Intercept variance & & $0.13^{* *}$ & & $0.13^{* *}$ & & $4^{* *}$ & & $0.22^{* *}$ \\
\hline
\end{tabular}

Adjusted variables included gender, education, position, clinical experience, work department, and extent of nurses' experience for non-nursing tasks. Age was eliminated from the analysis model because multicollinearity between age and clinical experience was found.

OR, odds ratio; $\mathrm{Cl}$, confidence interval; NWPDM, participation in the decision-making process; NWNP, nursing process; NWSTF, nurse-staffing adequacy; NWEDU, education to improve the quality of care; NWOSM, organizational support and management of the hospital; NWDNR, doctor-nurse relationship. ${ }^{*} p<0.05,{ }^{* *} p<0.01$.

infections, pressure sores, and medication errors. According to the findings of previous studies, the most frequent patient adverse events reported by nurses from the four major countries (the US, Canada, Germany, and Switzerland) was nosocomial infections followed by patient falls and medication errors $[7,16]$.

Nursing practice environment variables affecting nurse-perceived adverse events varied depending on the type of patient adverse event. Of the nursing practice environment variables found to be significant at the nursing level, the doctor-nurse relationship was related with nosocomial infections, and the doctor-nurse relationship and nursing process were associated with the incidence of pressure sores. For nurse-perceived nosocomial infections, organizational support and management of the hospital and nurse-staffing adequacy were significant in a previous study [16]. Unlike those findings, our study found the doctor-nurse relationship to be a significant nursing practice environment variable that affects nurse-perceived nosocomial infections. In addition, the doctor-nurse relationship and nursing process were significantly related with the perceived occurrence of pressure sores, but no correlation was found in previous studies $[16,21]$. One reason for this discrepancy might be because previous studies did not categorize the nursing processes as a nursing practice environment variable. Further studies should be conducted to examine the mechanism that explains how the nursing process is associated with the occurrence of pressure sores.

The nursing practice environment variables found to be significant at a hospital level include education to improve the quality of care, which was associated with patient falls, the doctor-nurse relationship, and organizational support and management of the hospital, both of which were associated with medication errors. Previous studies reported that no nursing practice environment variable affected patient falls $[16,21]$. However, in the present study, education to improve the quality of care, a hospital-level variable related to nursing practice environment was found to affect nurse-perceived patient falls. Education to improve the quality of care was significantly correlation with patient falls. Four items were used to measure this variable including whether an active skill development program and clinical experience development program is available for nurses on a regular basis as well as a preliminary education program for novice nurses. Last, whether hospitals supported new and innovative ideas about patient care was used to measure education to improve patient care. We expect that an education program focusing on quality care will reduce the occurrence of patient falls perceived by nurses.

The nursing practice environment variables significantly related to medication errors were the doctor-nurse relationship 
(at the hospital and nursing level), nursing process (nursing level only), and nursing staff adequacy (nursing level only). Previous studies found the doctor-nurse relationship [23], organizational support and management of the hospital [16,23], and nurse-staffing adequacy [16] to affect nurse-perceived medication errors. The doctor-nurse relationship and organizational support and management of the hospital was also significantly correlated in the present study. The doctor-nurse relationship was significantly correlated with nurse-perceived medication errors. Three items in the questionnaire were used to measure the doctor-nurse relationship. First, nurses were asked whether they felt doctors and nurses have good working relationships, nurses and doctors frequently work together as a team, and doctors provide high quality medical care. According to our findings, maintaining the doctor-nurse relationship might decrease the occurrence of medication errors perceived by nurses.

In our study, nurse-staffing adequacy increased the occurrence of nurse-perceived medication errors, but the bed-tonurse ratio was not significantly related. In fact, the level of correlation between nurse-staffing adequacy and medication errors varied in previous studies. In the Swiss study, nurse-staffing adequacy was a significant variable for all of the nurse-perceived patient adverse events (medications errors, nosocomial infections, and pressure sores) except for patient falls [16]. However, in the Canadian study, it was not correlated with medication errors or nosocomial infections [21]. Thus, further studies are needed to examine the relationship between nursestaffing adequacy and patient adverse events.

The present study has several limitations. First, this study was conducted on nurses working at general inpatient wards, so special conditions in specialized wards were not considered. Second, we were only able to analyze the nurse and hospital levels, not the ward level because some hospitals had few respondents $(<10)$; therefore, respondents were not evenly distributed across the different wards. Third, our study participants were limited to nurses who were members of the Korean Health and Medical Workers Union, thus may have different perspectives from non-unionized nurses. Despite these limitations, this study used data from 23 tertiary general hospitals and 37 non-tertiary general hospitals (both the private and public hospitals); therefore, we believe it is an important initial step in the evaluation of patient adverse events in Korean hospitals.

In conclusion, we found that nurse-perceived patient adverse events were higher in Korean hospitals than that reported in the US, Canada, Switzerland, and Germany. Promoting favorable doctor-nurse relationships and improving nurse practice environments that support the doctor-nurse team may help decrease the occurrence of patient adverse events.

\section{CONFLICT OF INTEREST}

The authors have no conflicts of interest with the material presented in this paper.

\section{REFERENCES}

1. Cho SH. Nurse staffing and adverse patient outcomes [dissertation]. Michigan: University of Michigan; 2002.

2. Michel P, Quenon JL, de Sarasqueta AM, Scemama O. Comparison of three methods for estimating rates of adverse events and rates of preventable adverse events in acute care hospitals. BMJ 2004;328(7433):199.

3. De Vries EN, Ramrattan MA, Smorenburg SM, Gouma DJ, Boermeester MA. The incidence and nature of in-hospital adverse events: a systematic review. Qual Saf Health Care 2008;17(3): 216-223.

4. Kohn LT, Corrigan J, Donaldson MS. To err is human: building a safer health system. Washington, DC: National Academy Press; 2000 , p. 18

5. Leape LL, Brennan TA, Laird N, Lawthers AG, Localio AR, Barnes $B A$, et al. The nature of adverse events in hospitalized patients. Results of the Harvard Medical Practice Study II. N Engl J Med 1991;324(6):377-384.

6. Thomas EJ, Studdert DM, Burstin HR, Orav EJ, Zeena T, Williams EJ, et al. Incidence and types of adverse events and negligent care in Utah and Colorado. Med Care 2000;38(3):261-271.

7. Aiken LH, Clarke SP, Sloane DM, Sochalski JA, Busse R, Clarke H, et al. Nurses' reports on hospital care in five countries. Health Aff (Millwood) 2001;20(3):43-53.

8. Lake ET, Shang J, Klaus S, Dunton NE. Patient falls: association with hospital magnet status and nursing unit staffing. Res Nurs Health. 2010;33(5):413-425.

9. Tervo-Heikkinen T, Partanen P, Aalto P, Vehvilainen-Julkunen K. Nurses' work environment and nursing outcomes: a survey study among Finnish university hospital registered nurses. Int J Nurs Pract 2008;14(5):357-365.

10. Flood AB. The impact of organizational and managerial factors on the quality of care in health care organizations. Med Care 
Rev 1994;51(4):381-428.

11. Kwon YJ, Lim YD. A study of enacting the patient safety and quality improvement act. Dankook Law Rev 2012;36(2):605-633.

12. Nam MH, Kang SH. The cognition level on the patient safety and safe nursing activities among hospital nurses in Busan. Health Soc Sci 2010;28:197-221.

13. Kim KN, Kang KJ, Lee HS, Shin YH, Kim SK, Park KH, et al. Survey on pressure ulcers and influencing factors of stage change in acute university hospital inpatients. J Korean Clin Nurs Res 2011;17(3):433-442.

14. Kim CW, Lee SY, Kang JH, Park BH, Park SC, Park HK, et al. Application of revised nursing work index to hospital nurses of South Korea. Asian Nurs Res (Korean Soc Nurs Sci) 2013;7(3): 128-135.

15. Health Insurance Review and Assessment. Hospital details information; 2010 [cited 2014 Sep 25]. Available from: http://www. hira.or.kr/rd/hosp/getHospList.do?pgmid=HIRAA030002000000 (Korean).

16. Schubert M, Glass TR, Clarke SP, Aiken LH, Schaffert-Witvliet $B$, Sloane DM, et al. Rationing of nursing care and its relationship to patient outcomes: the Swiss extension of the International Hospital Outcomes Study. Int J Qual Health Care 2008;20(4): 227-237.
17. Wilson RM, Runciman WB, Gibberd RW, Harrison BT, Newby L, Hamilton JD. The quality in Australian Health Care Study. Med J Aust 1995;163(9):458-471.

18. Vincent C, Neale G, Woloshynowych M. Adverse events in British hospitals: preliminary retrospective record review. BMJ 2001;322(7285):517-519.

19. Davis P, Lay-Yee R, Briant R, Ali W, Scott A, Schug S. Adverse events in New Zealand public hospitals I: occurrence and impact. N Z Med J 2002;115(1167):U271.

20. Baker GR, Norton PG, Flintoft V, Blais R, Brown A, Cox J, et al. The Canadian Adverse Events Study: the incidence of adverse events among hospital patients in Canada. CMAJ 2004;170(11): 1678-1686.

21. McCusker J, Dendukuri N, Cardinal L, Laplante J, Bambonye L. Nursing work environment and quality of care: differences between units at the same hospital. Int J Health Care Qual Assur Inc Leadersh Health Serv 2004;17(6):313-322.

22. Al-Kandari F, Thomas D. Perceived adverse patient outcomes correlated to nurses' workload in medical and surgical wards of selected hospitals in Kuwait. J Clin Nurs 2009;18(4):581-590.

23. Flynn L, Liang Y, Dickson GL, Xie M, Suh DC. Nurses' practice environments, error interception practices, and inpatient medication errors. J Nurs Scholarsh 2012;44(2):180-186. 